\title{
The Effect of Nanoparticles on Thermal Efficiency of Double Tube Heat Exchangers in Turbulent Flow
}

\author{
Reza Aghayari, ${ }^{1}$ Heydar Madah, ${ }^{1}$ Bahram Keyvani, ${ }^{2}$ \\ Abdolreza Moghadassi, ${ }^{3}$ and Fatemeh Ashori ${ }^{1}$ \\ ${ }^{1}$ Department of Chemistry, Islamic Azad University, Arak Branch, Arak 38361-1-9131, Iran \\ ${ }^{2}$ Department of Chemistry, Islamic Azad University, Saveh Branch, Saveh 39197-15179, Iran \\ ${ }^{3}$ Department of Chemical Engineering, Faculty of Sciences, University of Arak, Arak 38156-8-8349, Iran \\ Correspondence should be addressed to Reza Aghayari; reza.aghayari63@yahoo.com
}

Received 7 February 2014; Accepted 11 March 2014; Published 27 March 2014

Academic Editors: M. Al-Nimr and M. Yürüsoy

Copyright (C) 2014 Reza Aghayari et al. This is an open access article distributed under the Creative Commons Attribution License, which permits unrestricted use, distribution, and reproduction in any medium, provided the original work is properly cited.

\begin{abstract}
This paper refers to the Overall Heat Transfer Coefficient of Nano Fluids (OHTCNF) in heat exchangers and the relevant effective parameters. An improvement in Heat Transfer (HT) and OHTCNF containing nanoaluminum oxide with ca. $20 \mathrm{~nm}$ particle size and particular volume fraction in the range of 0.001-0.002 has been reported. The effects of temperature and concentration of nanoparticles on HT variation as well as Overall Heat Transfer Coefficient (OHTC) in a countercurrent double tube heat exchanger with turbulent flow have been studied. The experimental results show a remarkable $8 \%-10 \%$ rise in the mean HT and the OHTC. Accordingly, with an increase in the processing temperature and/or particle concentration the OHTC was observed to increase.
\end{abstract}

\section{Introduction}

Application of nanotechnology in classical thermal designs lead to nanofluid (NF) as a new class of heat transfer fluids. Since conventional HT fluids including water, oil, and Ethylene Glycol (EG) show relatively poor HT characteristics, NF has been introduced. By dispersing solid particles, fibers, or tubes of 1 to $50 \mathrm{~nm}$ length in conventional HT fluids, NFs are formed. There are remarkable characteristics associated with NFs such as high HT rate, low fluctuation ability through passages, and thermal homogeneity. In this view, NFs found extensive demand in electronics and automotive industries to name but a little. Consequently, further study of HT of NF suspensions seemed necessary. Ever since Choi [1] published the first findings in NFs studies, there have been several other works addressed to the improvement of HT up to $20 \%$ by using densely distribution of nanoparticles in NFs [2-5]. Efforts were carried out for better comprehension of changes in heat transfer coefficient in heat exchangers. Heat transfer coefficient of NFs with very low particle volume \% is much higher as referred to the base fluid. On the other hand, low changes in friction coefficient and fluid viscosity in NFs have been reported [6-12]. Xuan and Roetzel [13] in their investigation on random motion of nanoparticles in NF noticed an increase in energy transfer rate. An experimental study on the convectional HT and flow characteristics of water-Cu NF through a straight pipe with constant thermal flow under laminar and turbulent regimes has been reported. Nanoparticles of $\mathrm{Cu}$ with less than $100 \mathrm{~nm}$ diameter were employed. The results show that nanosuspended particles substantially improved the performance of conventional base fluid HT. The volume fraction of base fluid in NF fits well with that of water. Furthermore, new convectional HT relations were established to foresee HT coefficients in both laminar and turbulent flows [14, 15]. Recently, Khanafer et al. [16] discussed the similar results obtained from a fundamental simulation work. In spite of remarkable potentials in NFs, few steps have been made so far. Further research works on the effect of nanoparticles on fluid heat transfer are inevitable. Accordingly, it is necessary to obtain experimental data from fluids containing variety of nanosized particles. Further studies are yet to be completed on the effective 


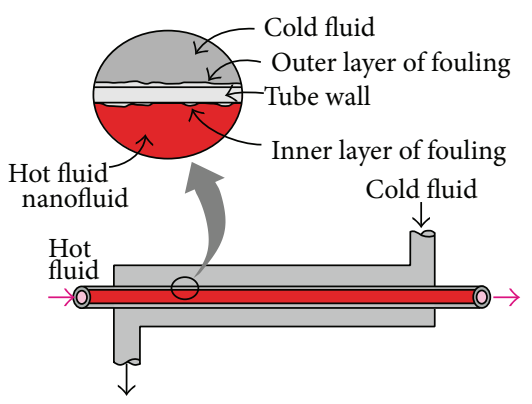

(a)

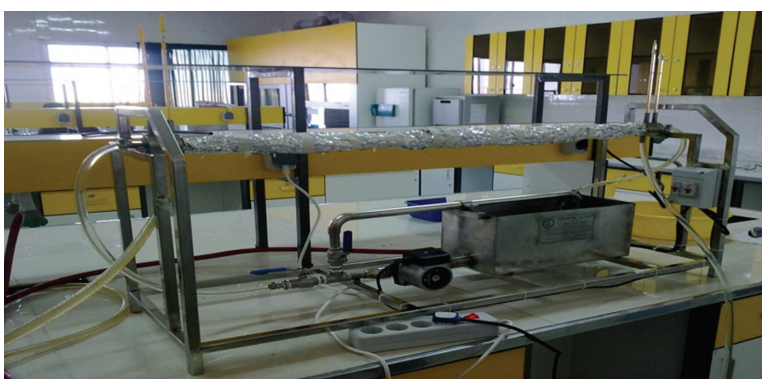

(b)

Figure 1: Schematic presentation of the apparatus.

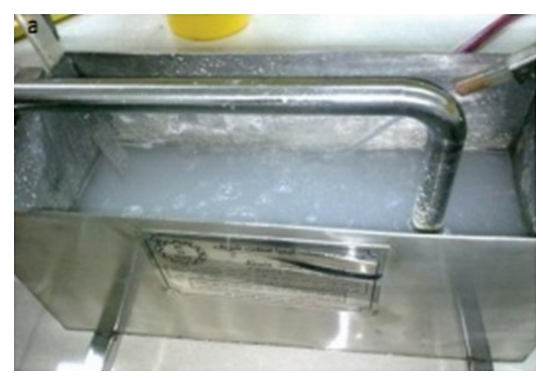

(a)

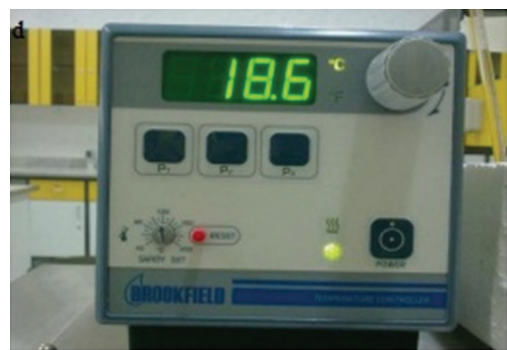

(d)

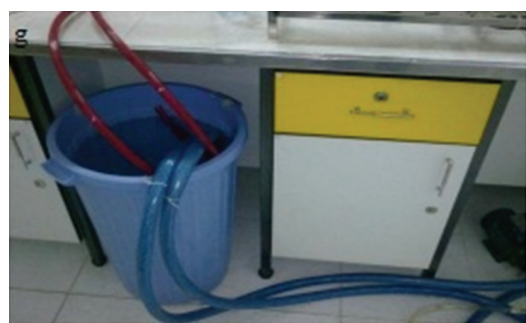

(g)

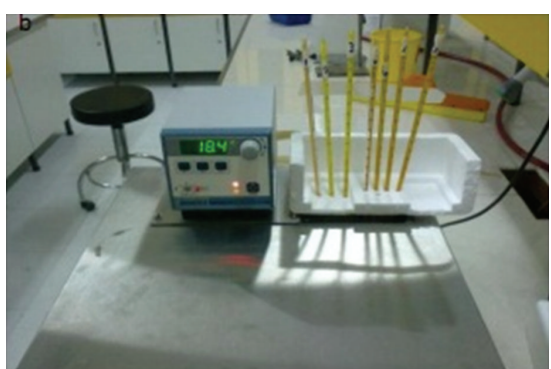

(b)

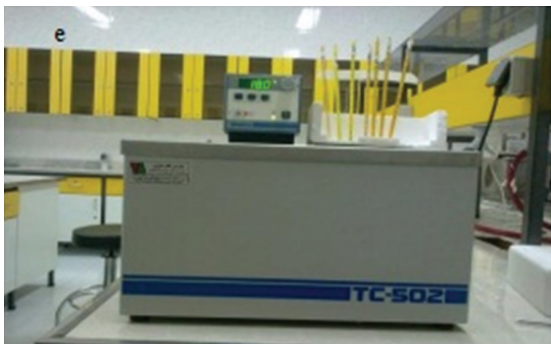

(e)

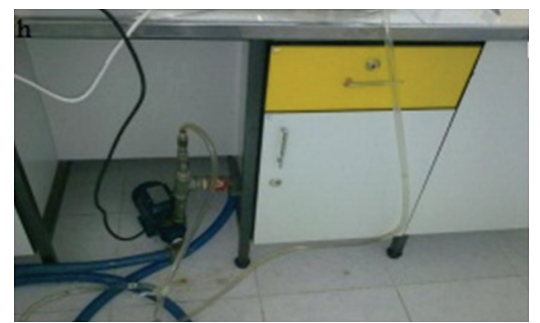

(h)

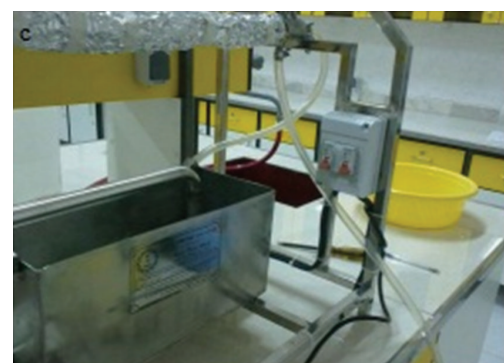

(c)

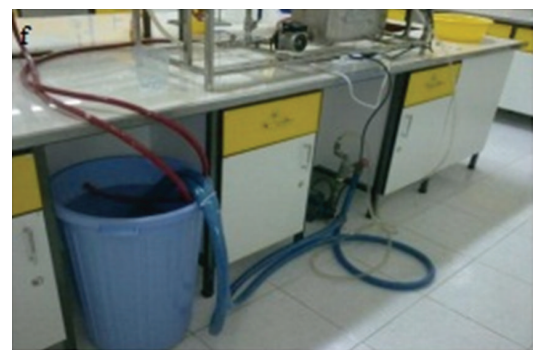

(f)

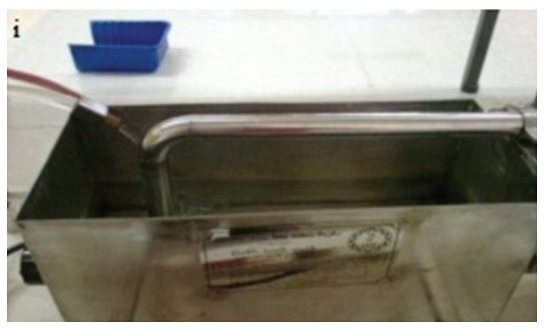

(i)

FIGURE 2: Images of different parts of the apparatus test chamber.

parameters including surface structure, nanoparticle shape, irregular particle distribution, and nanoparticle motion that play important role in nanofluids HT. Such studies will pave the path to introduce the mechanism for increased HT in NFs. There are varieties of apparatus developed to measure HT coefficient in fluids containing nanometric particles. Experimental findings on the effect of aluminum oxide nanoparticles have been argued on HT in double tube heat exchangers.

\section{Apparatus}

The apparatus employed in this work is schemed in Figures 1 and 2 . The device comprises a test chamber, two storage tanks, and two magnetic gear pumps: one to circulate NF known as "hot fluid" while the other to pump cooling fluid in a loop. The test chamber is a double tube countercurrent heat exchanger $120 \mathrm{~cm}$ long. The NF flows inside the tube while cooling fluid (water) flows through the outer tube. The inner tube is made 


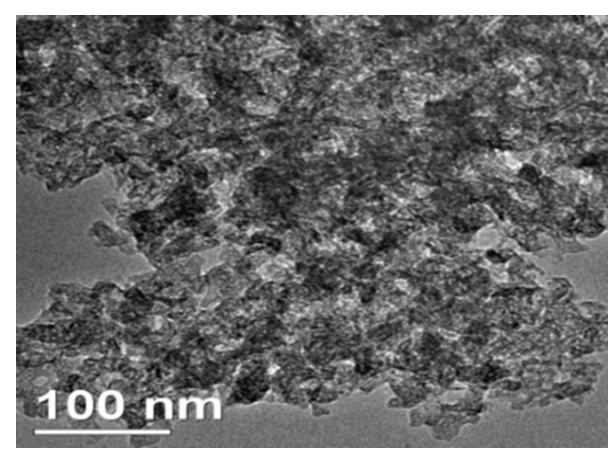

FIgure 3: The SEM image of $\mathrm{Al}_{2} \mathrm{O}_{3}$ nanoparticles.

from soft copper $6 \mathrm{~mm}$ ID and $8 \mathrm{~mm}$ OD. The outer tube is made from steel $14 \mathrm{~mm}$ ID and $16 \mathrm{~mm}$ OD. Plastic insulator is used for the upper and lower sections of the test chamber to reduce the heat loss. The test chamber is equipped with four thermometers located at the input and output streams of both hot NF and cooling fluid. The two storage tanks each 15 and 80 liters volume are made from stainless-steel and plastic to store hot NF and cooling water. The NF storage tank is equipped with an electric heater and a thermostat to maintain the temperature of hot NF. Accordingly, the water storage tank is equipped with a cooling device and a thermostat to maintain the temperature of cooling water.

\section{Data Processing}

The Heat Transfer Coefficient of Nano-Fluid (HTCNF) can be calculated by pursuing the following procedure.

From (1), the HT rate $q_{\mathrm{NF}}$ is determined by means of collecting the experimental data and using physical properties of $N F$ including the mass flow rate; $m_{\mathrm{NF}}$, fluid heat capacity; $C_{p, \mathrm{NF}}$, and changes in the temperature of hot nanofluid passing through test chamber $T_{\mathrm{NF}, \mathrm{OUT}}$ and $T_{\mathrm{NF}, \mathrm{IN}}$

$$
\begin{gathered}
q_{\mathrm{NF}}=m_{\mathrm{NF}} C_{P, \mathrm{NF}}\left(T_{\mathrm{NF}, \mathrm{OUT}}-T_{\mathrm{NF}, \mathrm{IN}}\right), \\
q_{\text {ColdWater }}=m_{\text {ColdWater }} C_{P, \mathrm{ColdWater}}\left(T_{\mathrm{CW}, \mathrm{IN}}-T_{\mathrm{CW}, \mathrm{OUT}}\right), \\
\frac{q_{\mathrm{CW}}+q_{\mathrm{NF}}}{2} .
\end{gathered}
$$

The overall heat transfer coefficient of nanofluid; $U$, is determined from (4), where HT surface area, $A$, and HT rate, $q$, are obtained experimentally

$$
U=\frac{q}{A \cdot \Delta T_{\mathrm{LMTD}}}=\frac{m_{\mathrm{NF}} C_{P, \mathrm{NF}}\left(T_{\mathrm{NF}, \mathrm{OUT}}-T_{\mathrm{NF}, \mathrm{IN}}\right)}{A \cdot \Delta T_{\mathrm{LMTD}}} .
$$

Equation (5) addresses the use of mean logarithmic changes in temperatures and LMTD of the inlet and outlet streams, that is, Hot NF and cooling water calculated from the experimental data.

$$
\Delta T_{\mathrm{LMTD}}=\frac{\left(T_{\mathrm{NF}, \mathrm{OUT}}-T_{\mathrm{COLD}, \mathrm{IN}}\right)-\left(T_{\mathrm{NF}, \mathrm{IN}}-T_{\mathrm{COLD}, \mathrm{OUT}}\right)}{\ln \left(\left(T_{\mathrm{NF}, \mathrm{OUT}}-T_{\mathrm{COLD}, \mathrm{IN}}\right) /\left(T_{\mathrm{NF}, \mathrm{IN}}-T_{\mathrm{COLD}, \mathrm{OUT}}\right)\right)} .
$$

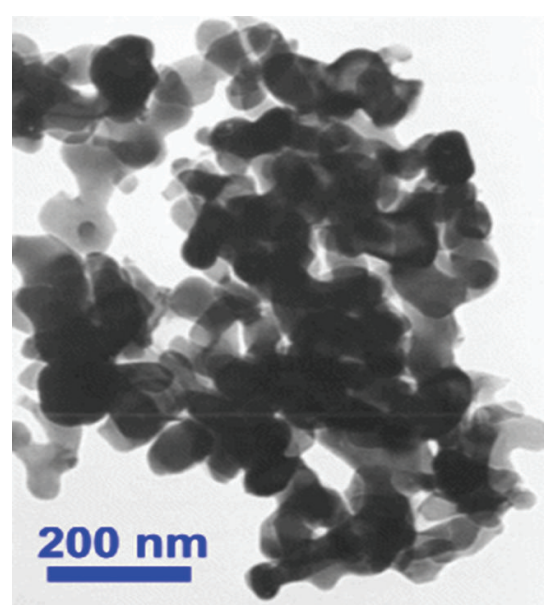

Figure 4: The TEM image of $\mathrm{Al}_{2} \mathrm{O}_{3}$ nanoparticles.

From (6), the overall heat transfer coefficient of the heat exchanger is determined from the fluid inlet and outlet convective heat transfer coefficients $h_{i}$ and $h_{o}$, respectively, the inner tube wall conductive heat transfer coefficient, $k_{w}$, and inner tube wall thickness, $\delta_{w}$

$$
\frac{1}{U}=\frac{1}{h_{i}}+\frac{\delta_{w}}{k_{w}}+\frac{1}{h_{o}}
$$

Equation (7) refers to the substituted values in (6), where tube diameter and surface area, $D$ and $A$, respectively, are derived from design values, the subscripts $i$, and $o$ assigned for the inner and outer tubes

$$
\frac{1}{U}=\frac{1}{h_{i}\left(A_{i} / A_{o}\right)}+\frac{D_{o}}{2 k} \ln \frac{D_{o}}{D_{i}}+\frac{1}{h_{o}} .
$$

\section{Sample Preparation}

Preparation of nanofluids require precise composition of solid nanoparticles dispersed in a base fluid. Accordingly the prepared dispersion should be kept stable. Commonly, there are three methods to avoid settling the particles as follows:

(1) to control the $\mathrm{pH}$ of the dispersion,

(2) introducing surfactants,

(3) the use of ultrasonic method.

The aforementioned methods affect the surface properties of suspended nanoparticles and cluster formation does not occur. Therefore, dispersions become stable.

Aluminum oxide nanoparticles $20 \mathrm{~nm}$ diameter laboratory grade was dispersed in cetyl trimethyl aluminum bromide (CTAB) from Merk and was used at low concentration as surface active agent (surfactant). Initially, CTAB was dissolved and diluted in distilled water. This solution guarantees adequate dispersion and stability of nanoparticles without scarifying physical and thermal properties of nanofluid. In the next step, various nanofluid (NF) samples were made by means of introducing few drops of $\mathrm{Al}_{2} \mathrm{O}_{3}$ nanoparticles 


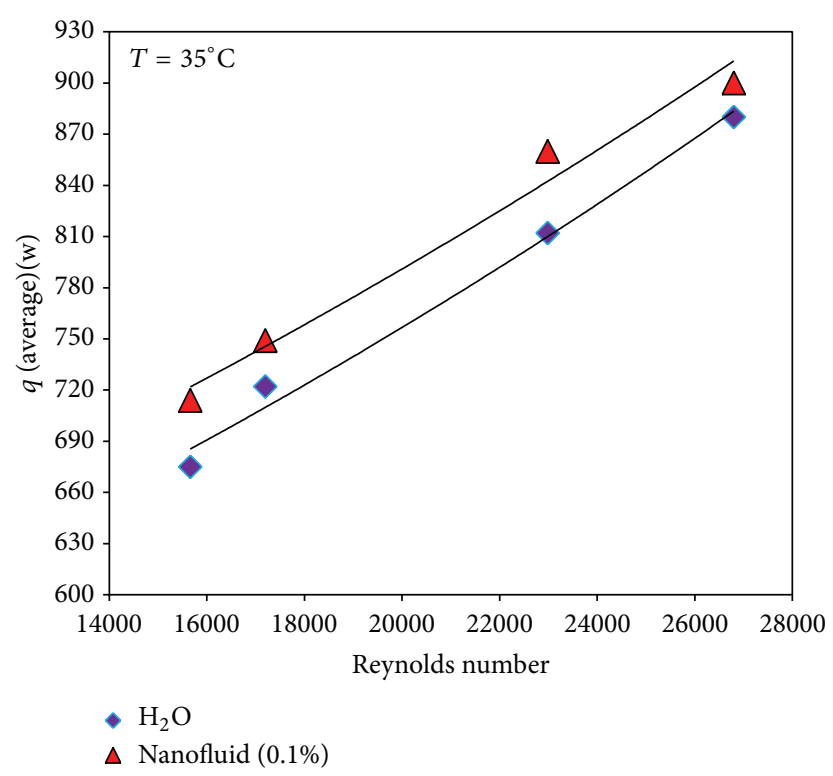

(a)

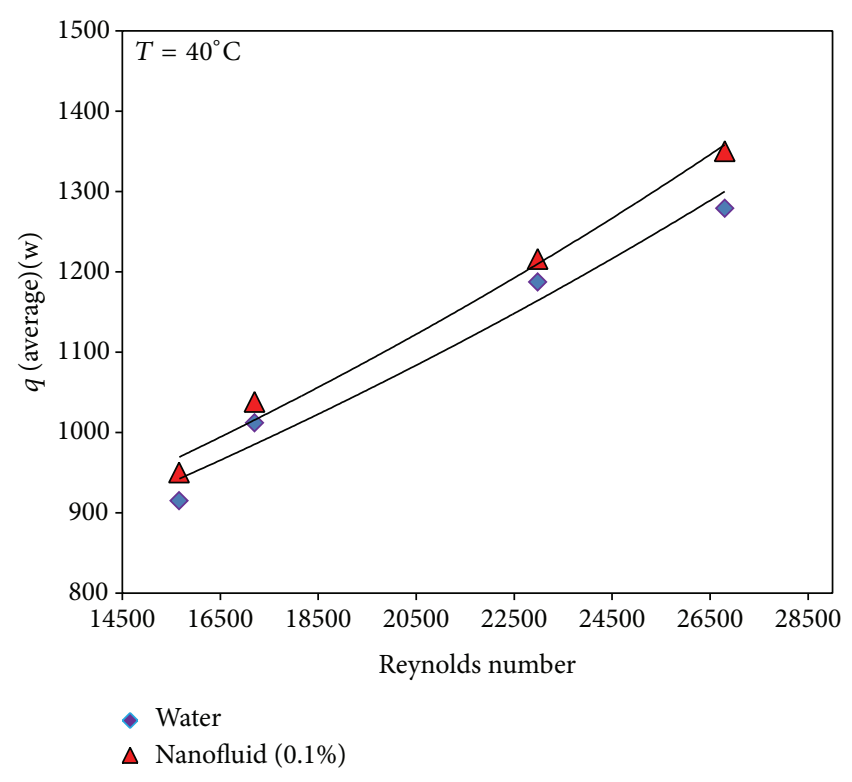

(b)

FIGURE 5: Variation of mean heat flow rate with Reynolds number for NF $0.1 \%$ and water at (a) $35^{\circ} \mathrm{C}$ and (b) $40^{\circ} \mathrm{C}$.

dispersed in $\mathrm{CTAB}$ solution in various quantities of water as base fluid. The volume fraction of $\mathrm{Al}_{2} \mathrm{O}_{3}$ nanoparticles in NF samples varied from 0.1 to $0.2 \%$. NF samples were then underwent mixing by ultrasonic method between 3 to 4 hours to ensure complete dispersion is achieved. The morphology of $\mathrm{Al}_{2} \mathrm{O}_{3}$ nanoparticles was studied by using SEM and TEM.

\section{Results and Discussion}

Figures 3 and 4 represent the morphology of nanoaluminum particles by means of using SEM and TEM, respectively.

When using aluminum oxide NF as hot fluid, the heat transfer rate increases as opposed to that of water, that is, base fluid. This finding is depicted in Figure 5 where at Reynolds number equals 16000; the mean HT rate values for water at $35^{\circ} \mathrm{C}$ and $40^{\circ} \mathrm{C}$ are approximated to 675 and 915 Watts, respectively. As for NF $0.1 \%(\mathrm{v} / \mathrm{v})$ at identical Reynolds number the mean HT rate values at the above noted temperatures are 700 and 950 Watts, respectively. The values of OHTCNF as compared to those of the base fluid in both laminar and turbulent regimes are higher. One explanation would be to attribute the affecting parameters including Reynolds numbers for the hot and cold fluid, the size of nanoparticles, the type of heat exchanger, and NF temperature to such rises. Figure 6 refers to the dependency of OHTCNF to Reynolds number. According to this figure, as Reynolds number and temperature increase in NF containing $\mathrm{Al}_{2} \mathrm{O}_{3} \quad 0.2 \%(\mathrm{v} / \mathrm{v})$ in water as base fluid, the OHTCNF increases. For the sake of argument, at Reynolds number equals 26000 for water at $35^{\circ} \mathrm{C}$ and $40^{\circ} \mathrm{C}$ the OHTCNF values are 2300 and 2500 , respectively.

The experimental results show that $\mathrm{Al}_{2} \mathrm{O}_{3} \mathrm{NF}$ has higher overall heat transfer efficiency in comparison with water as base fluid. When nanoparticle concentration increases in NF, the overall heat transfer coefficient rate increases even faster. If mass flow rate increases, then rise in temperature has severe effect on the overall heat transfer coefficient. Therefore, not only nanoparticle concentration but also the NF operating temperature and the corresponding effects on dispersion would all affect the heat transfer of NF. It is worth noting that particle surface properties and heat exchanger design are important and must be taken into consideration.

\section{Conclusion}

In general, there are three mechanisms to improve heat transfer by introducing nanoparticles into the base fluid.

(a) Nano-particles benefit higher heat transfer rate; therefore, as nanoparticle concentration in the base fluid increases the heat transfer rate increases accordingly.

(b) The collisions occur between nanoparticles and the base fluid molecules on the one hand and the impacts of the particles to the heat exchanger wall on the other hand result in an energy increase.

(c) The friction between the wall and fluid increases if NFs are dealt with and, therefore, heat transfer improves.

Based on the experimental results, introducing nanoparticles to the fluid will increase heat transfer coefficient of the system in both laminar and turbulent regimes. Surface properties, particle shape, and concentration of nanoparticles play important role to improve NF heat transfer properties. The elevated heat transfer coefficient may attribute to the higher concentrations of nanoparticles adjacent to the wall caused by particle migration phenomenon. The momentum 


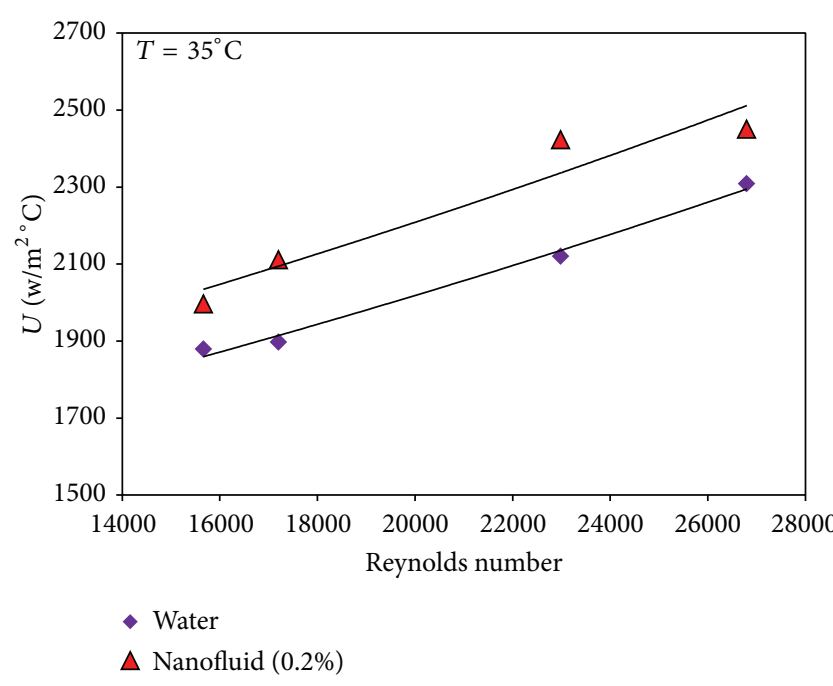

(a)

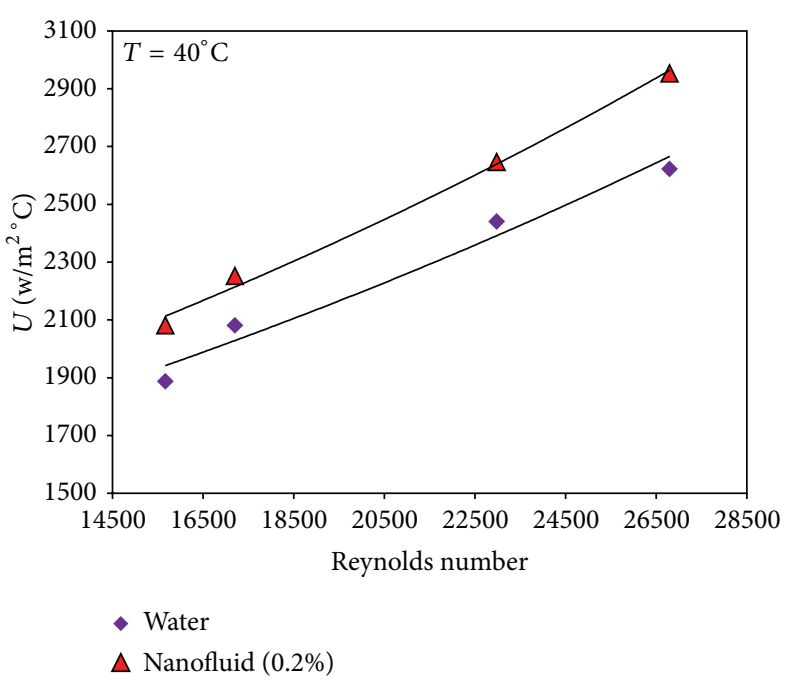

(b)

Figure 6: Variation of overall heat transfer coefficient with Reynolds number for NF $0.2 \%$ and water at (a) $35^{\circ} \mathrm{C}$, (b) $40^{\circ} \mathrm{C}$.

of suspended particles increases as the NF mass flow rate increases. Accordingly, the collision of nanoparticles to the wall becomes even more intense. Friction to the wall as a function of wall surface properties and NF characteristics may need to be studied. Further research is required to better understand the NF heat transfer properties and develop more relations.

\section{Conflict of Interests}

The authors declare that there is no conflict of interests regarding the publication of this paper.

\section{References}

[1] S. U. S. Choi, Development and Applications of Non-Newtonian Flows, ASME, New York, NY, USA, 1995.

[2] S. U. S. Choi, Z. G. Zhang, W. Yu, F. E. Lockwood, and E. A. Grulke, "Anomalous thermal conductivity enhancement in nanotube suspensions," Applied Physics Letters, vol. 79, no. 14, pp. 2252-2254, 2001.

[3] J. A. Eastman, S. U. S. Choi, S. Li, W. Yu, and L. J. Thomson, "Anomalously increased effective thermal conductivities of ethylene glycol-based nanofluids containing copper nanoparticles," Applied Physics Letters, vol. 78, no. 6, p. 718, 2001.

[4] H. Xie, J. Wang, T. G. Xi, Y. Liu, and F. Ai, "Thermal conductivity enhancement of suspensions containing nanosized alumina particles," Journal of Applied Physics, vol. 91, no. 7, p. 4568, 2002.

[5] T. H. Cho, S. D. Park, Y. S. Lee, and I. H. Baek, Korean Chemical Engineering Research, vol. 42, p. 624, 2004.

[6] Y. Xuan and Q. Li, "Investigation on convective heat transfer and flow features of nanofluids," Journal of Heat Transfer, vol. 125, no. 1, pp. 151-155, 2003.

[7] G. Roy, C. T. Nguyen, and P. R. Lajoie, "Numerical investigation of laminar flow and heat transfer in a radial flow cooling system with the use of nanofluids," Superlattices and Microstructures, vol. 35, no. 3-6, pp. 497-511, 2004.

[8] D. Wen and Y. Ding, "Experimental investigation into convective heat transfer of nanofluids at the entrance region under laminar flow conditions," International Journal of Heat and Mass Transfer, vol. 47, no. 24, pp. 5181-5188, 2004.

[9] Y. Yang, Z. G. Zhang, E. A. Grulke, W. B. Anderson, and G. Wu, "Heat transfer properties of nanoparticle-in-fluid dispersions (nanofluids) in laminar flow," International Journal of Heat and Mass Transfer, vol. 48, no. 6, pp. 1107-1116, 2005.

[10] C. H. Lee, S. W. Kang, and S. H. Kim, Journal of Industrial and EngineeringChemistry, vol. 11, p. 152, 2005.

[11] P. Keblinski, S. R. Phillpot, S. U. S. Choi, and J. A. Eastman, "Mechanisms of heat flow in suspensions of nano-sized particles (nanofluids)," International Journal of Heat and Mass Transfer, vol. 45, no. 4, pp. 855-863, 2001.

[12] S. P. Jang and S. U. S. Choi, "Role of Brownian motion in the enhanced thermal conductivity of nanofluids ", Applied Physics Letters, vol. 84, no. 21, p. 4316, 2004.

[13] Y. Xuan and W. Roetzel, "Conceptions for heat transfer correlation of nanofluids," International Journal of Heat and Mass Transfer, vol. 43, no. 19, pp. 3701-3707, 2000.

[14] Q. Li and Y. Xuan, "Convective heat transfer and flow characteristics of $\mathrm{Cu}$-water nanofluid," Science in China, Series E: Technological Sciences, vol. 45, no. 4, pp. 408-416, 2002.

[15] Y. Xuan and Q. Li, "Investigation on convective heat transfer and flow features of nanofluids," Journal of Heat Transfer, vol. 125, no. 1, pp. 151-155, 2003.

[16] K. Khanafer, K. Vafai, and M. Lightstone, "Buoyancy-driven heat transfer enhancement in a two-dimensional enclosure utilizing nanofluids," International Journal of Heat and Mass Transfer, vol. 46, no. 19, pp. 3639-3653, 2003. 

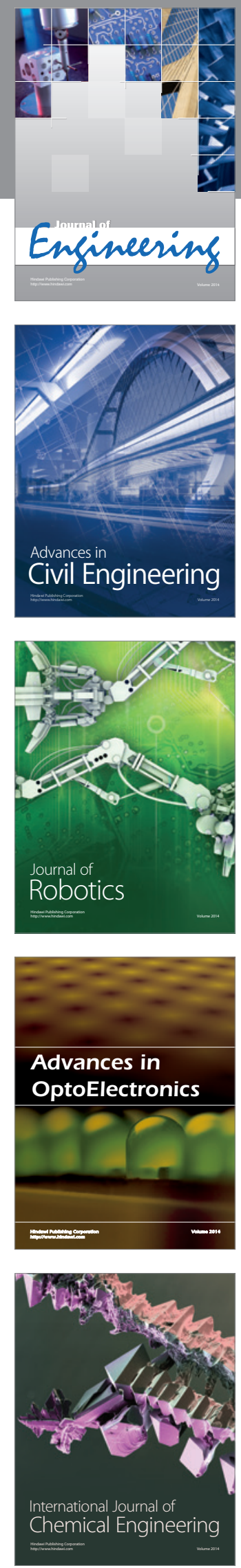

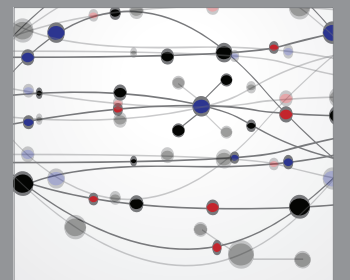

The Scientific World Journal
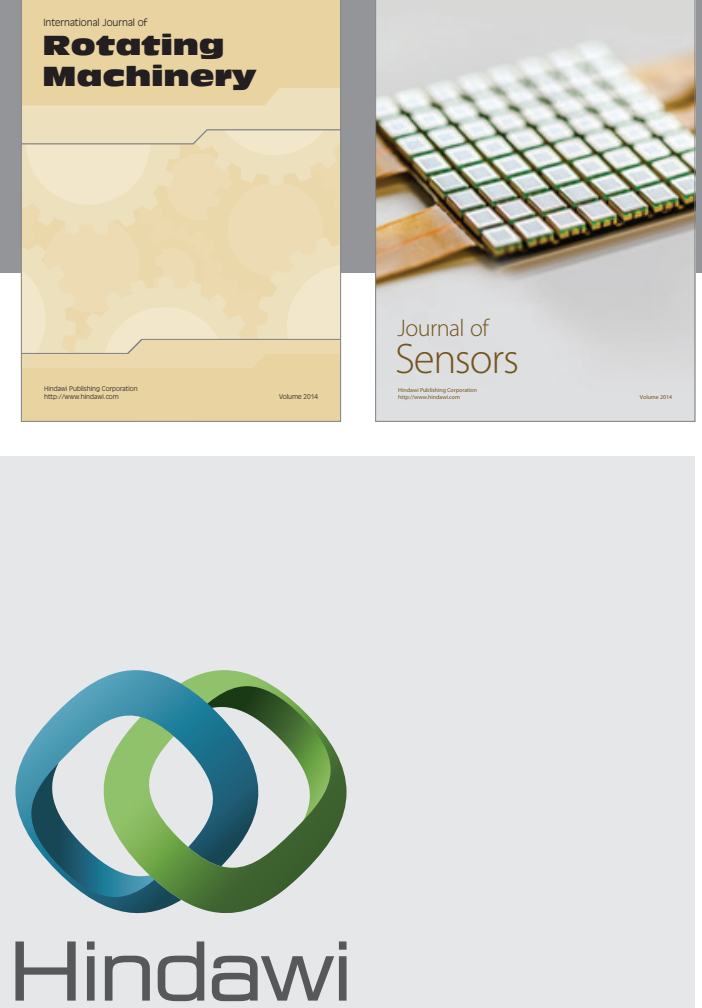

Submit your manuscripts at http://www.hindawi.com
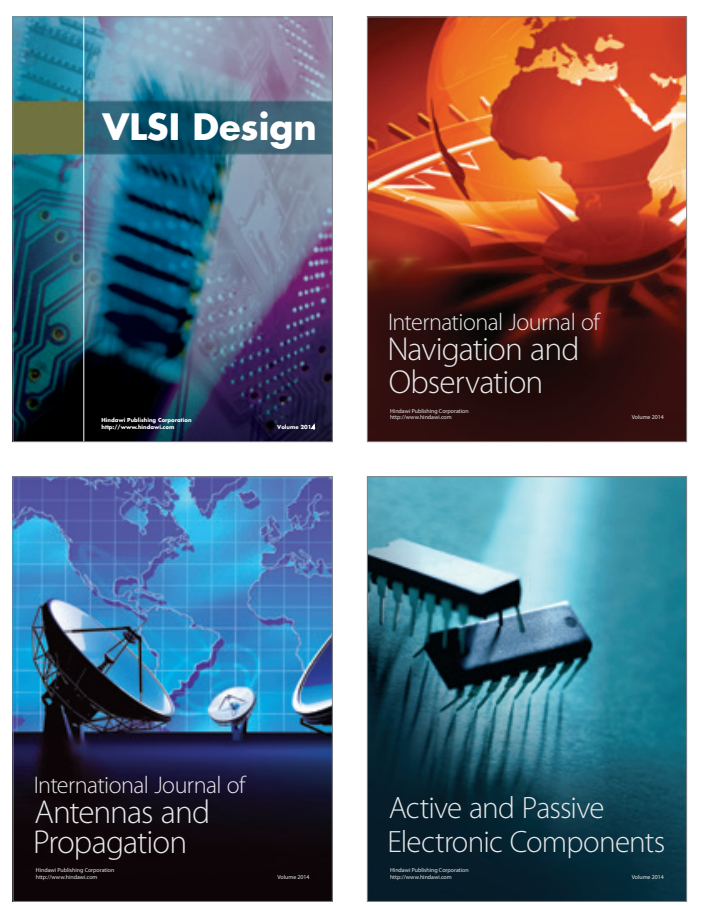
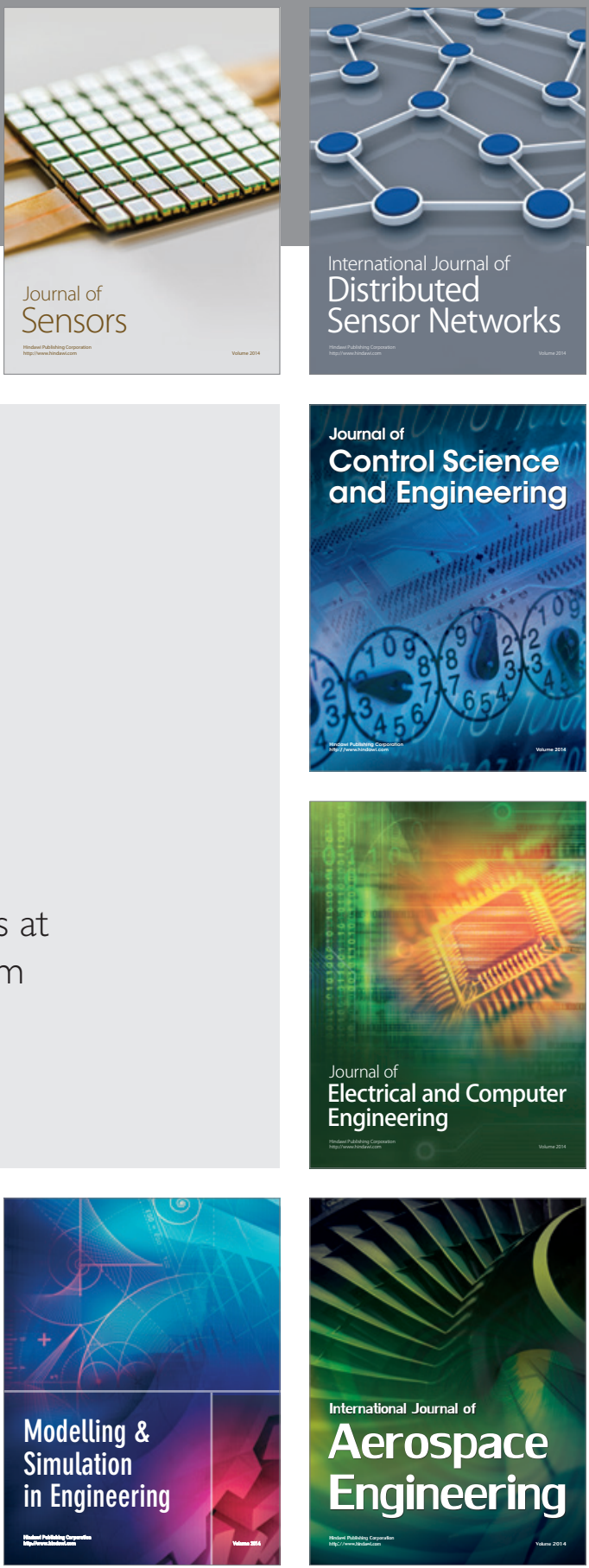

Journal of

Control Science

and Engineering
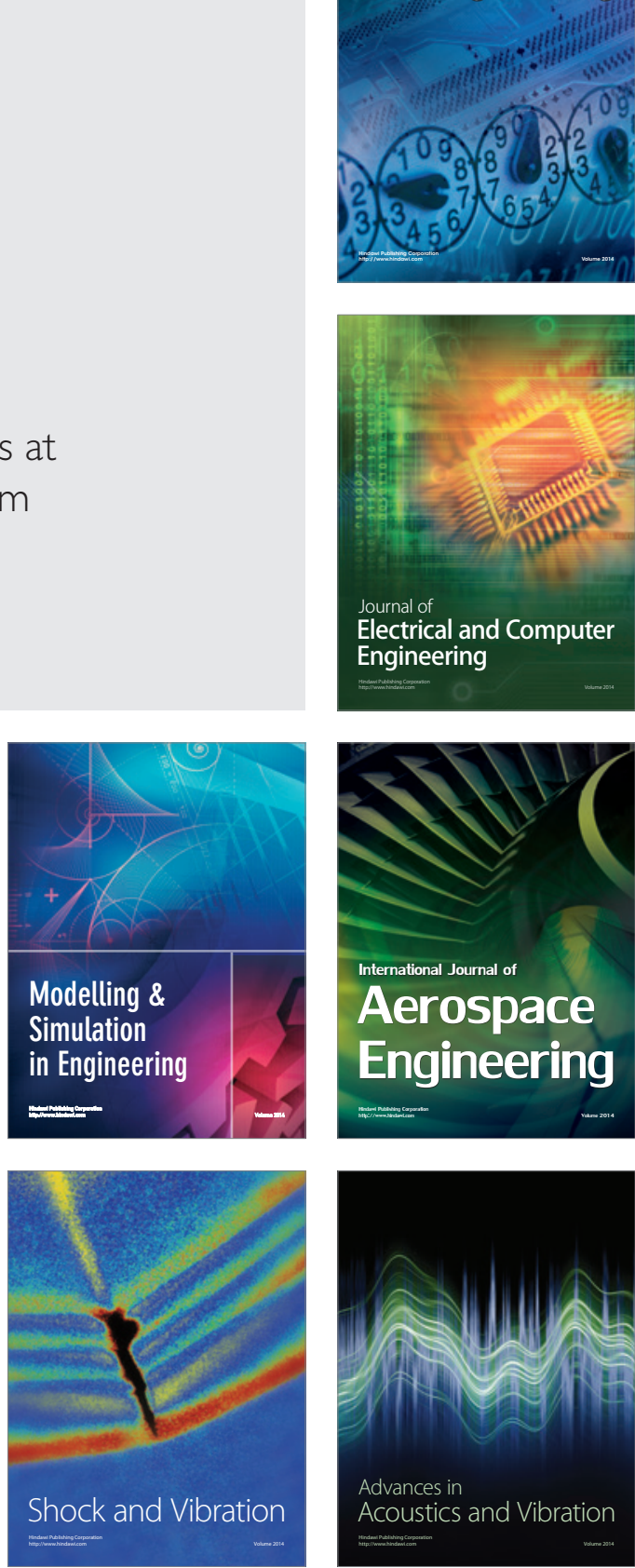